\title{
Hierarchical population structure analysis of the milkweed beetle, Tetraopes tetraophthalmus (Forster)
}

\author{
David E. McCauley and \\ Walter F. Eanes
}

\author{
Department of General Biology, Vanderbilt \\ University, Nashville, TN 37235, U.S.A., and \\ Department of Ecology and Evolution, SUNY at \\ Stony Brook, Stony Brook, NY 11794, U.S.A.
}

The population structure of the milkweed beetle Tetraopes tetraophthalmus (Forster) is tied intimately to the biology of its one host plant, Asclepias syriaca. The patchy distribution of the host plant and the limited dispersal of the beetle combine to organise the herbivore into numerous very localised populations. An analysis of hierarchical patterns of spatial variation in allozyme frequencies by means of Wright's $F$-statistics reveals that in some parts of the beetle's range this population structure can result in moderate genetic differentiation $(F=0.03-0.06)$ among beetle populations inhabiting milkweed patches separated by only a few kilometres. Substantial differentiation occurs across the range of the species $(F=0 \cdot 154)$. A review of similar studies shows the values of $F$ calculated for $T$. tetraophthalmus to be among the highest found for a flying insect. It is argued that the local differentiation results, in part, from a reduction in effective population sizes associated with the ephemeral nature of milkweed patches and that this population structure is favourable for the operation of Wright's Shifting Balance mode of evolution.

\section{INTRODUCTION}

The spatial organisation of local populations and concomitant patterns of gene flow are important determinants of the potential for a species to become genetically differentiated over its geographic range. This is true whether the agent of differentiation is spatial variation in selection pressures or the chance effects of genetic drift. The study of population structure and associated gene flow in natural populations can take two approaches, one ecological and one genetic (Slatkin, 1985a). Ecological studies of the dispersal of individuals or their gametes use various mark and recapture schemes to attempt to measure gene flow directly, and can be used to make predictions about the population structure of a species. In contrast, surveys of geographic patterns of gene frequency variation that utilise electrophoretic markers can be used to make inferences about ecological parameters such as average local population size and rates of migration (e.g., Larson et al., 1984; Slatkin, $1985 b$ ). The genetic data is often summarised by the use of $F$-statistics as suggested by Wright (1978) for the analysis of population structure. Both approaches have been applied to the study of the population structure in a diversity of species, though rarely are both approaches applied together. From recent reviews that have compiled $F$-statistic data for numerous animal species (i.e., Eanes and Koehn, 1978; Wright, 1978; Ayala, 1982; Barrowclough, 1983) it can be seen that, not surprisingly, there is a general agreement between the relative degree of population structure as measured by $F(S \times T)$ and the perceived vagility of the species in question. For example, among animal species, sedentary groups such as land snails and salamanders tend to have relatively high values of $F(S \times T)$, while most species of flying birds and insects have rather low values.

A further refinement of the application of $F$ statistics to the analysis of population structure involves hierarchical analysis. Here the total geographic component of genetic variance is partitioned into subcomponents due to (a) variance among closely spaced local populations likely to be exchanging migrants and (b) variance among groups of populations defined on a greater geographic scale. In one such analysis Selander and Whitham (1983) argue that localised measures of $F(S \times T)$ are most likely to reflect the effects of population structure and gene flow. Hierarchical $F$-statistic analysis was developed by Wright as part of his Shifting Balance theory of evolution in 
which some evolutionary transitions due to the joint effects of selection, drift, and migration are possible in highly structured populations but can not occur in large panmictic units (Wright, 1977; 1978).

The milkweed beetle Tetraopes tetraophthalmus (Forster) (Coleoptera: Cerambycidae) has been the focus of several ecological studies of dispersal and gene flow (McCauley et al., 1981; McCauley, 1983). These studies have concluded that the limited dispersal of the insect, combined with the patchy, island-like distribution of its host plant, the common milkweed Asclepias syriaca, organise the species into thousands of local populations across its range in eastern North America. Thus, the species would appear to have the potential for a high degree of genetic differentiation across its geographic range and should exhibit genetic differences between populations separated by as little as a few kilometres. The one limited genetic study of this species (Eanes et al., 1977) used polymorphic allozyme markers to document allele frequency heterogeneity among seven collections of T. tetraophthalmus taken from individual milkweed patches located in Suffolk Co., N.Y.

Here, we report on gene frequency variation at three polymorphic loci derived from a more systematic and hierarchical collection of beetles taken across a broad geographic area. The collections were designed to examine whether the degree of local population structure documented by Eanes et al. (1977) in New York is representative of other localised regions across the species' range, and also to estimate the total geographic component of genetic variance. Groups of milkweed patches were sampled on an individual patch basis within four $30 \times 30 \mathrm{~km}$ regions, the regions being spaced across a major portion of the range of the species. The data, when combined with that reported by Eanes et al. (1977) are used in a hierarchical $F$ statistic analysis that partitions the total geographic component of genetic variance into components due to among patch variance within the local regions and a component among regions. The results are discussed in the context of the known ecology of the beetle and its host plant, as well as in the context of a survey of $F$-statistics calculated for other species of insects.

\section{MATERIALS AND METHODS}

Tetraopes tetraophthalmus is a univoltine beetle whose adults and larvae feed almost exclusively on the common milkweed, Asclepias syriaca.
Adults can be found on the foliage of the host plant from June until August, depending on location. Adult beetles were collected from individual milkweed patches according to a hierarchical collecting scheme. Milkweed patches were defined as nearly discrete aggregations of milkweed stalks occupying from about 0.25 to 10 ha. All beetles collected from the same patch are considered to belong to the same population or random breeding unit as evidenced by dispersal studies (McCauley, 1983). Some number of populations (4-19) were sampled from each of 5 localities called regions. Each region consisted of an area of less than $30 \times$ $30 \mathrm{~km}$. Regions were defined in southern New Hampshire (NH), southwest Virginia (VA), middle Tennessee (TN), and northern Illinois (ILL). Collections were made in New Hampshire in 1983, Illinois in 1984, and Tennessee in 1985. Most Virginia populations were sampled in 1984, though a few localities were sampled in 1983 or 1985 . All data presented for a particular population are derived from a single generation. Because of the univoltine nature of this species only two generations separate the 1983 and 1985 collections. In addition, data taken from collections made on Long Island, New York (NY) in 1975 and described by Eanes et al. (1977) were used to constitute a fifth region. Fig. 1 presents these regional locations against the range of the host plant as described by Chemsak (1963).

Beetles were stored at $-70^{\circ} \mathrm{C}$ until they could be prepared for starch gel electrophoresis. Eanes et al. (1977) present data for leucine aminopeptidase (LAP) and phosphoglucomutase (PGM), the only polymorphic loci they found in their original survey. In that survey amylase, glucose-6phosphate dehydrogenase, glutamate oxaloacetate transaminase, isocitrate dehydrogenase, lactate dehydrogenase, peptidase and phosphoglucoisomerase were resolved but found to be monomorphic (Eanes, unpubl.). Similar techniques were followed for the resolution of LAP and PGM in the more recent samples with the following exceptions. Both enzymes could be resolved with an electrode buffer described as "salamander B" by Werth (1985) and a gel buffer consisting of a 1:9 dilution of the electrode buffer. B-mercaptoethanol was added to the grinding buffer to stabilise the PGM electromorphs. A more recent enzyme survey was able to resolve two additional enzymes, malic enzyme and hexokinase. Hexokinase (HK) proved to be polymorphic when resolved with a tris-citrate electrode buffer ( $\mathrm{pH} \mathrm{8.0)}$ ). The discovery of the HK polymorphism came after the onset of the Virginia collecting. As a consequence not all Virginia popu- 


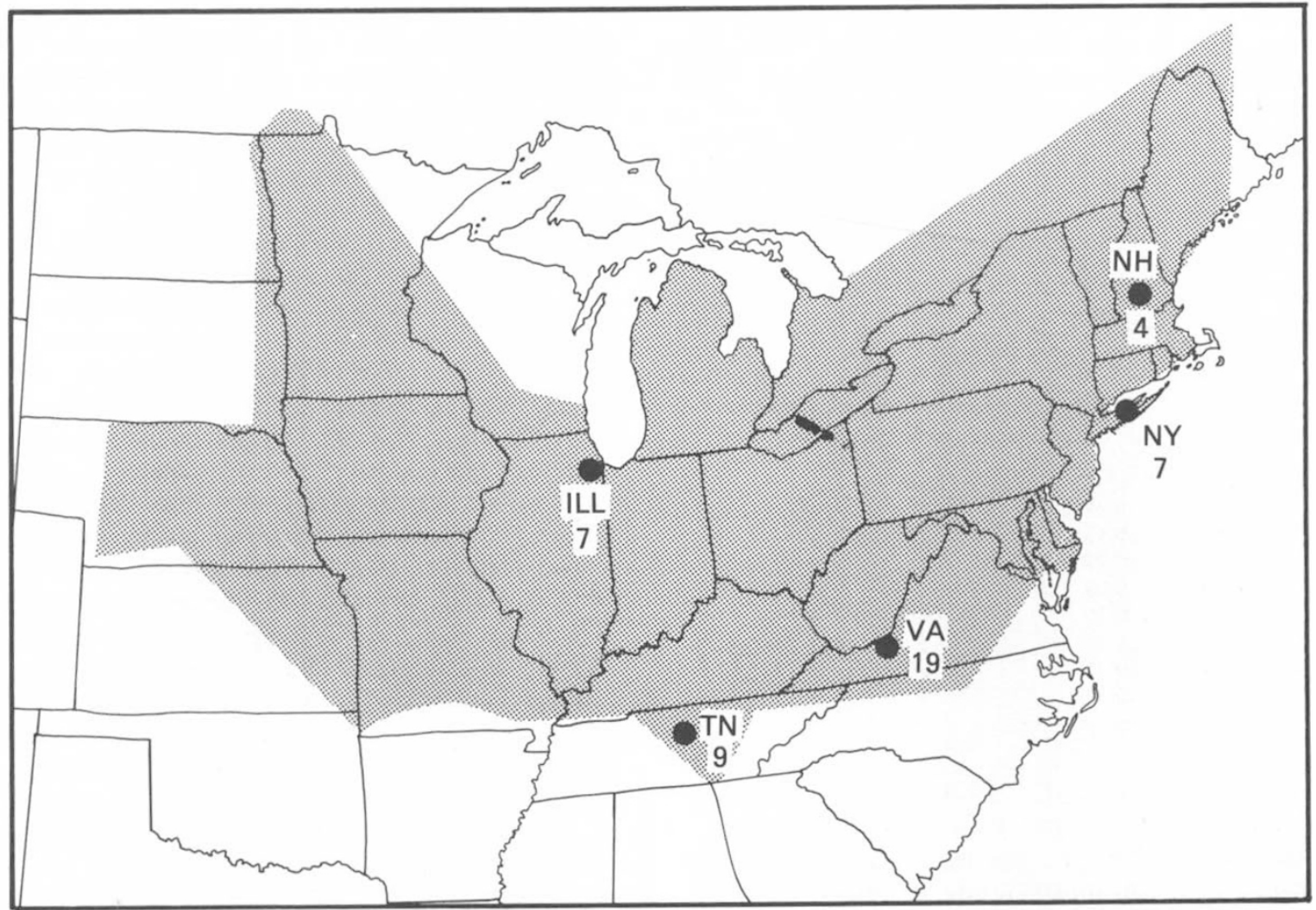

Figure 1 The location of five regions from which adult Tetraopes tetraophthalmus were collected. Numbers refer to the number of individual milkweed patches sampled in each region. Stippled area defines the range of the host plant, Asclepias syriaca as described by Chemsak (1963).

lations were assayed for HK. Samples from various regions were occasionally run side by side to standardise allelic nomenclature.

Gene frequency variation was quantified by hierarchical $F$-statistics as suggested for the study of population structure by Wright (1978). See Weir and Cockerham (1984) and Slatkin (1985a) for recent discussions of the application of $F$-statistics to population structure analysis. Geographic variation in gene frequencies was computed among populations within regions, $F(P \times R)$, among regions relative to the total $F(R \times T)$, and finally among populations relative to the total, $F(P \times T)$. Specific computations followed the methods of Weir and Cockerham (1984). That reference also describes methods used when more than two alleles were found at a given locus and methods used to combine information across loci. Occasionally values of $F(P \times R)$ were computed to be very slightly negative owing to sample size corrections and were set to zero.

\section{RESULTS}

Results are presented as allele frequencies and sample sizes for LAP, PGM and HK in tables 1-3 respectively. All populations sampled expressed two electrophoretic alleles for LAP (named $F$ and $S)$, though there was considerable variation in frequency from region to region. PGM expressed a total of three alleles $(F, M, S)$, though only NY populations were strongly polymorphic for all three alleles. Only the $M$ and $S$ alleles were found in NH and $F$ and $M$ in VA. In ILL the populations were nearly fixed for the $M$ allele but both $F$ and $S$ appeared occasionally. Tennessee populations were monomorphic for the $M$ allele. Hexokinase expressed two common alleles $(F, S)$ in $\mathrm{NH}, \mathrm{TN}$ and VA, with the $S$ variant being quite rare in ILL.

A statistical comparison of the fit of the observed genotypic ratios to Hardy-Weinberg expectations was made for each locus for each population by use of $G$-Goodness of Fit tests 
Table 1 Allele frequencies and sample sizes for LAP

\begin{tabular}{|c|c|c|c|c|c|}
\hline Locality & $n$ & $P_{F}$ & Locality & $n$ & $P_{F}$ \\
\hline NH-1 & 84 & 0.44 & VA-6 & 61 & 0.47 \\
\hline 2 & 72 & 0.38 & 7 & 40 & 0.38 \\
\hline 3 & 71 & 0.43 & 8 & 69 & 0.53 \\
\hline 4 & 74 & 0.37 & 9 & 27 & 0.46 \\
\hline$N Y-1$ & 316 & 0.45 & 10 & 50 & 0.36 \\
\hline 2 & 199 & 0.35 & 11 & 52 & 0.43 \\
\hline 3 & 287 & 0.49 & 12 & 43 & 0.47 \\
\hline 4 & 321 & $0 \cdot 31$ & 13 & 84 & 0.42 \\
\hline 5 & 309 & 0.35 & 14 & 38 & 0.43 \\
\hline 6 & 430 & 0.55 & 15 & 97 & 0.37 \\
\hline 7 & 259 & 0.44 & 16 & 70 & 0.40 \\
\hline ILL-1 & 51 & $0 \cdot 21$ & 17 & 57 & 0.37 \\
\hline 2 & 91 & $0 \cdot 20$ & 18 & 60 & 0.48 \\
\hline 3 & 59 & $0 \cdot 15$ & 19 & 70 & 0.44 \\
\hline 4 & 91 & $0 \cdot 16$ & TN-1 & 38 & 0.68 \\
\hline 5 & 50 & $0 \cdot 17$ & 2 & 102 & 0.82 \\
\hline 6 & 60 & $0 \cdot 17$ & 3 & 44 & 0.69 \\
\hline 7 & 69 & $0 \cdot 17$ & 4 & 60 & 0.67 \\
\hline VA-1 & 124 & 0.39 & 5 & 50 & 0.63 \\
\hline 2 & 55 & $0 \cdot 30$ & 6 & 46 & 0.82 \\
\hline 3 & 39 & 0.37 & 7 & 20 & 0.82 \\
\hline 4 & 52 & 0.37 & 8 & 60 & 0.81 \\
\hline 5 & 69 & 0.33 & 9 & 64 & 0.69 \\
\hline
\end{tabular}

(Sokal and Rohlf, 1981). (PGM in TN and PGM and HK in ILL did not express sufficient polymorphism to warrant such tests.) Of 98 tests, 9 showed a deviation from the expected HardyWeinberg distribution that was significant at the 0.05 or lower level. Of these, 4 showed a heterozy- gote deficiency, 5 a heterozygote excess. Ignoring statistical significance, 49 of the total expressed a heterozygote deficiency and 49 a heterozygote excess. Thus, there are no consistent deviations from Hardy-Weinberg in our data set that would indicate pervasive substructuring within our sample units.

Values of $F(P \times R)$ calculated for each locus for each region are presented in table 4 . The value presented for PGM in the NY sample is that averaged across the 3 alleles by the methods of Weir and Cockerham (1984). No value is calculated for PGM in TN because the locus is monomorphic in that region. In order to test whether estimates of $F(P \times R)$ greater than zero truly reflect heterogeneity in gene frequencies among populations, the association of allelic frequencies with populations was tested for each locus in each region by $G$ contingency analysis (Sokal and Rohlf, 1981) with the results included in table 4. Table 4 also provides an estimate of $F(P \times R)$ calculated for each region by combining information across loci. Information combined across loci should provide the most accurate reflection of the true population structure.

While it can be seen that there are no consistent locus-specific trends, there do appear to be between-region differences in local population structure. For example, while there is no measurable genetic differentiation among the ILL popula-

Table 2 Allele frequencies and sample sizes for PGM

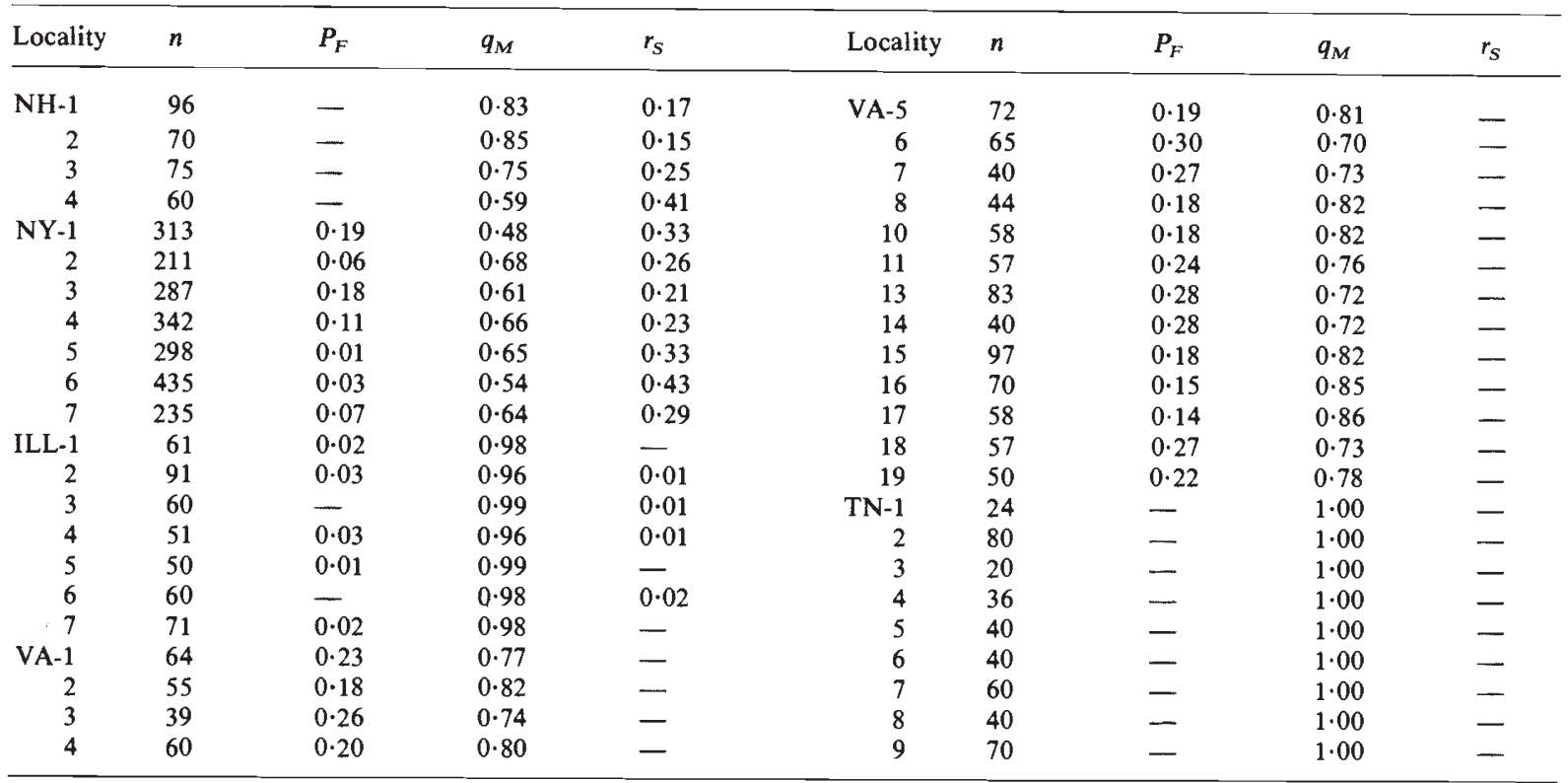


Table 3 Allele frequencies and sample sizes for $\mathrm{HK}$

\begin{tabular}{rlrrrl}
\hline Locality & $n$ & $P_{F}$ & Locality & $n$ & $P_{F}$ \\
\hline NH-1 & 57 & 0.85 & VA-7 & 59 & 0.76 \\
2 & 61 & 0.57 & 8 & 68 & 0.74 \\
3 & 35 & 0.81 & 10 & 51 & 0.74 \\
4 & 26 & 0.81 & 11 & 63 & 0.80 \\
ILL-1 & 51 & 0.98 & 14 & 53 & 0.69 \\
2 & 87 & 0.97 & 15 & 46 & 0.76 \\
3 & 53 & 0.93 & 17 & 39 & 0.78 \\
4 & 85 & 0.95 & 18 & 51 & 0.75 \\
5 & 50 & 0.92 & 19 & 49 & 0.71 \\
6 & 61 & 0.96 & TN-2 & 95 & 0.44 \\
7 & 70 & 0.96 & 3 & 43 & 0.51 \\
VA-1 & 53 & 0.78 & 4 & 33 & 0.39 \\
2 & 42 & 0.75 & 5 & 45 & 0.52 \\
4 & 29 & 0.86 & 6 & 41 & 0.67 \\
5 & 71 & 0.74 & 8 & 40 & 0.45 \\
6 & 60 & 0.72 & 9 & 58 & 0.66 \\
\hline
\end{tabular}

Table $4 F(P \times R)$ values as calculated for each locus at each region as well as average values for each region

\begin{tabular}{lllll}
\hline Region & LAP & PGM & HK & Average \\
\hline VA & $0.005^{*}$ & $0.006^{*}$ & 0.000 & 0.003 \\
TN & $0.023^{* * *}$ & - & $0.036^{* * *}$ & 0.031 \\
ILL & 0.000 & 0.001 & 0.001 & 0.000 \\
NH & 0.000 & $0.064^{* * *}$ & $0.095^{* * *}$ & 0.064 \\
NY & $0.033^{* * *}$ & $0.031^{* * *}$ & - & 0.031
\end{tabular}

Note: Asterisks represent significance levels in $G$ contingency tests of the independence of allele frequencies among populations within regions. ${ }^{*}=p<0.05,{ }^{* *}=p<0.01,{ }^{* * *}=p<0.001$

tions, NH, NY and TN populations exhibit considerable differentiation. While Weir and Cockerham (1984) present methods for estimating variance in $F$, we are not aware of any standard statistical methods for comparing $F$ statistics. In order to test for heterogeneity among regions in $F(P \times R)$ values, we performed the following analysis based on the Scheffe-Box test suggested by Sokal and Rohlf (1981) as a test for the homogeneity of variances. This test includes computations that require the individual variates, in this case allele frequencies. $F(S T)$ is often considered as the variance in gene frequencies standardised by the product of the mean gene frequencies $\left(S_{p}^{2} / \bar{p} \bar{q}\right)$. Thus, to make a comparison of allele frequency variances using the Scheffe-Box test relevant to a comparison of $F(P \times R)$ estimates we had to standardise the individual gene frequencies for each population so that the variance of the gene frequencies within each region became equal to their respective $F(P \times R)$ values calculated above. This was accomplished by dividing the gene frequency estimate for each population by the square root of the product of the regional means $(\sqrt{p} \bar{q})$. After performing this transformation on the data presented in tables 1-3, the ScheffeBox test was performed across regions separately for each locus. There was highly significant heterogeneity among regions in the standardised variance in LAP $(p<0.001)$. Variance in PGM and $\mathrm{HK}$ showed no statistically significant heterogeneity among regions $(p>0 \cdot 10)$. We note that the statistical power associated with the PGM and HK tests is less than that associated with LAP owing to a smaller number of samples. In sum, there is partial support for our view that regions vary in their local population structure.

Calculations of the degree of among region differentiation, $F(R \times T)$, are presented for each locus and combined across loci in table 5 . Since the New York samples were taken 8-10 generations prior to the more recent collections, two calculations are presented, one with and one without the New York data. They are in close agreement. The total geographic differentiation, $F(P \times T)$, combined across loci and including the New York data is $0 \cdot 154$.

Table $5 F(R \times T)$ values as calculated for each locus and the average across loci

\begin{tabular}{lllll}
\hline$F(R \times T)$ & LAP & PGM & HK & average \\
\cline { 1 - 2 } With NY & 0.098 & 0.165 & 0.164 & 0.147 \\
Without NY & 0.184 & 0.159 & 0.164 & 0.172 \\
\hline
\end{tabular}

\section{DISCUSSION}

The results of the earlier dispersal and life-history studies and the present genetic study can be combined to form a comprehensive view of population structure in Tetraopes tetraophthalmus. Mark and recapture experiments (McCauley et al., 1981; Lawrence, 1982; McCauley, 1983) have shown that most adults do not move very far during their reproductive lives despite having the ability to fly. Most individuals stay in the milkweed patch in which they emerged. Generation-wide gene flow distance estimates derived from these dispersal studies become particularly small when net displacement distances of recaptured adults are weighted by the age-specific reproductive potential of the cohort at the time when each recapture was made (Endler, 1979; McCauley, 1983).

In contrast, a series of laboratory tethering experiments and field studies (Davis, 1981; 1984) 
has shown that adults of this species are physiologically capable of long distance flights and might occasionally disperse several kilometres from their point of birth. Thus, the combined dispersal studies suggest that the beetles found in a given milkweed patch do represent a breeding unit moderately isolated from similar populations in nearby patches, yet patches spaced several kilometres apart are theoretically capable of exchanging rare migrants. Thus, the population structure viewed over a few tens of square kilometres is similar to that studied in "stepping stone" models of population structure (Kimura and Weiss, 1964) in which most individuals breed in their natal population, a small fraction move to an adjacent population, and an even smaller fraction are capable of moving to any population in the array. This view of the population structure of the species is supported by the present withinregion $F$-statistic analysis which demonstrates that gene flow must be sufficiently limited at this spatial scale so as to permit some genetic differentiation of local populations.

The degree of local differentiation does not appear to be uniform across the species' range, however, and differentiation is non-existent in Illinois. This could be due to variation in the patchy distribution of the host plant. It was our observation that milkweed was much more abundant in the area of Illinois where we collected (western suburbs of Chicago) and there were fewer obvious barriers to gene flow compared with the other four collecting regions. Milkweed patches appeared more widely dispersed in the areas of New York, New Hampshire and Tennessee where collections were made and there were more intervening patches of forest. In southwest Virginia milkweed patches are rather closely spaced in the agriculturally developed valleys but these valleys are separated by heavily wooded ridges. An intriguing possibility is suggested by the work of Davis (1986). He found that in laboratory tethered-flight experiments females collected from regions where milkweed is relatively rare display greater average flight potential than do females collected from areas where milkweed is more common. Thus, regional variation in local population structure could be a consequence of variation in habitat structure, variation in the intrinsic vagility of the beetles, or an interaction of the two factors.

Genetic differentiation of populations could be due to spatial variation in selection pressures, genetic drift, or the joint effects of both processes. In order for genetic drift to influence among population variance in gene frequencies, effective popu- lation sizes must be moderately small. Mature milkweed patches can contain several thousand adult beetles. Average effective population sizes are undoubtedly considerably less than this, however, due to the ephemeral nature of milkweed patches. Asclepias syriaca is a disturbed habitat species primarily occupying old fields and roadsides. It must be subjected to frequent local extinctions and recolonisations. In the course of our studies we have seen several milkweed patches go extinct due to either human disturbance or natural successional changes. We therefore speculate that it is unlikely that a beetle population occupying a particular milkweed patch would persist for more than a maximum of $50-100$ generations. In that case the genetic characteristics of a beetle population could be partially influenced by chance events and associated founder effect at population initialisation and small population sizes in the generations immediately after the population was founded. Slatkin (1977) and Maruyama and Kimura (1980) derive mathematical models that relate various modes of colonisation to the accumulation of among population gene frequency variance and show that such variance can be generated by some patterns of local extinction and recolonisation. While the effects of extinction and recolonisation on population structure can be complex, under some circumstances episodes of extinction and recolonisation are thought to be favourable for the operation of Wright's "Shifting Balance" mode of evolution (Wright, 1977; Barton and Charlesworth, 1984; Lande, 1985). It is our view that $T$. tetraophthalmus displays a population structure very similar to that described by Wright $(1977,1978)$ as favourable for evolution by the Shifting Balance process.

It would be very useful, therfore, to document the initial colonisation and early demographic history of a local beetle population. Several factors critical to the genetic consequences of population foundation would include number, sex, and origin of initial founders, rate of population growth in the generations immediately succeeding colonisation, and the rate of arrival of new migrants following initial colonisation. Many of these factors must be determined, in turn, by the demography of the host plant; specifically the dispersal distances travelled by milkweed propagules colonising new habitat, the rate of expansion of young milkweed patches, and the rate of patch extinction.

While values of $F$ can theoretically range from 0 to 1 , we suggest that the $F(P \times R)$ values of $0.03-0.06$ measured over a very limited fraction of the species' total range and an $F(P \times T)$ greater 
than $0 \cdot 15$ represent a surprisingly high degree of population structure considering that this is an abundant, flying insect. Wright $(1969,1977,1978)$ suggests that population structures resulting in $F(S \times T)$ values as small as 0.05 can still favour the operation of Shifting Balance evolution. He notes that when a species is distributed into many local populations, even a small variance in gene frequency will generate occasional populations whose gene frequencies represent extreme outliers.

In order to contrast the genetic population structure of $T$. tetraophthalmus to other sexually reproducing, flying insects, we surveyed the recent literature for comparable studies. We found few that attempted to match the spatial scale of the collecting regime to the known dispersal biology of the insect (but see work done on checkerspot butterflies such as that reported in McKechnie et al., 1975, for an example of an approach to insect population structure that does combine ecological and genetic information). Even fewer studies replicated local collections in a hierarchical fashion. Table 6 presents some estimates of $F(S \times T)$ calculated from samples taken across a major portion of the respective species' ranges. These estimates would be comparable with our $F(P \times T)$. In some cases the data had been used by the authors to calculate genetic identities or distances rather than $F(S \times T)$ but an estimate of $F$ could be calculated from tabulated allelic frequencies and sample sizes provided in those references. The list is not intended to be an exhaustive survey but should be representative of recent work on insects. Studies in which the taxonomic rank of geographic populations was in question were not included. It can be seen that, when considered on a broad geographic scale, $T$. tetraophthalmus is one of the more geographically structured insect species. In fact,

Table 6 Values of Wright's $F($ st) estimated for 29 insect species

\begin{tabular}{|c|c|c|}
\hline Species & $F(\mathrm{st})$ & Reference \\
\hline \multicolumn{3}{|l|}{ Diptera } \\
\hline Musca autumnalis & 0.023 & Bryant et al. (1981) \\
\hline Rhagoletis completa (native range) & 0.007 & Berlocher (1984) \\
\hline R. completa (introduced range) & 0.054 & Berlocher (1984) \\
\hline Prosimulium fuscum & 0.003 & Snyder and Linton (1984) \\
\hline P. mixtum & 0.096 & Snyder and Linton (1984) \\
\hline Drosophila willistoni & 0.022 & cited in Ayala (1982) \\
\hline D. pseudoobscura & 0.028 & cited in Ayala (1982) \\
\hline D. equinoxialis & 0.029 & cited in Ayala (1982) \\
\hline D. obscura & 0.067 & cited in Ayala (1982) \\
\hline D. pavani & $0 \cdot 126$ & cited in Ayala (1982) \\
\hline \multicolumn{3}{|l|}{ Lepidoptera } \\
\hline Danaus plexippus & 0.009 & Eanes and Koehn (1978) \\
\hline Spodoptera frugiperda & 0.084 & Pashley et al. (1985) \\
\hline S. exempta & 0.006 & cited in Pashley et al. (1985) \\
\hline Alabama argillacea & 0.007 & cited in Pashley et al. (1985) \\
\hline Pieris rapae & 0.014 & cited in Pashley et al. (1985) \\
\hline Anticarsia gemmatalis & 0.021 & cited in Pashley et al. (1985) \\
\hline Heliothis virescens & 0.048 & cited in Pashley et al. (1985) \\
\hline Cydia pomonella & 0.066 & cited in Pashley et al. (1985) \\
\hline Euphydryas chalcedona & 0.090 & cited in Pashley et al. (1985) \\
\hline E. editha & 0.118 & cited in Pashley et al. (1985) \\
\hline \multicolumn{3}{|l|}{ Coleoptera } \\
\hline Dendroctonus ponderosae & 0.030 & Stock et al. (1984) \\
\hline D. frontalis & 0.068 & Anderson et al. (1979) \\
\hline Ips calligraphus & 0.011 & Anderson et al. (1983) \\
\hline Diabrotica barberi & 0.098 & McDonald et al. (1985) \\
\hline Leptinotarsa decemlineata & $0 \cdot 068$ & Jacobson and Hsiao (1983) \\
\hline Pissodes strobi & 0.098 & Phillips and Lanier (1985) \\
\hline Tetraopes tetraophthalmus & $0 \cdot 154$ & this study \\
\hline Hemiptera & 0.082 & Zera $(1981)$ \\
\hline \multicolumn{3}{|l|}{ Hymenoptera } \\
\hline Rhytidoponera confusa & $0 \cdot 294$ & Ward $(1980)$ \\
\hline R. chalybaea & $0 \cdot 380$ & Ward $(1980)$ \\
\hline
\end{tabular}


measures of geographic differentiation taken on a small spatial scale within parts of the range of milkweed beetles are comparable with the degree of differentiation found across the entire range of many other insect species.

Acknowledgements We thank W. S. Lawrence for providing us with the New Hampshire samples. E. C. Lawson, L. M. Reilly and R. A. Schedler provided invaluable field and laboratory assistance. Much of the work was done at the Mt. Lake Biological Station and we thank its directors and staff for their logistical support. This project was supported financially by grant BSR 83-20339 from the National Science Foundation and an award from the Vanderbilt University Research Council, both awards to DEM. Contribution no. 609 in Ecology and Evolution from the State University of New York at Stony Brook.

\section{REFERENCES}

ANDERSON, W. W., BERISFORD, C. W. AND KIMMICH, R. H. 1979. Genetic differences among five populations of the southern pine beetle. Ann. Entomol. Soc. Am., 72, 323-327.

ANDERSON, W. W., BERISFORD, C. W., TURNBOW, R. H. AND BROWN C. J., 1983. Genetic differences among populations of the black turpentine beetle, Dendroctonus terebrans, and an engraver beetle, Ips calligraphus (Coleoptera: Scolytidae). Ann. Entomol. Soc. Am., 76, 896-902.

AYALA, F. J. 1982. The genetic structure of species. Milkman, R. (ed.) In Perspectives on Evolution. Sinauer, Sunderland, MA, pp. 60-82.

BARROWCLOUGH, G. F. 1983. Biochemical studies of microevolutionary processes. Brush, A. H. and Clark, G. A. (eds.), In Perspectives in Ornithology, Cambridge Univ. Press, Cambridge, pp. 223-261.

BARTON, N. H. AND CHARLESWORTH, B. 1984. Genetic revolutions, founder effects, and speciation. Ann. Rev. Ecol. Syst., 15, 133-164.

BERLOCHER, S. H. 1984. Genetic changes coinciding with the colonization of California by the walnut husk fly, Rhagoletis completa. Evolution, 38, 906-918.

BRYANT, E. H., VAN DIJK, H. AND VAN DELDEN, W. 1981. Genetic variability of the face fly, Musca autumnalis De Geer, in relation to a population bottleneck. Evolution, 35, 872-881.

CHEMSAK, J. A. 1963. Taxonomy and bionomics of the genus Tetraopes (Coleoptera: Cerambycidae). Univ. Calif. Pub. in Entomol., 30, 1-90.

DAVIS, M. A. 1981. The flight capacity of dispersing milkweed beetles, Tetraopes tetraophthalmus. Ann. Entomol. Soc. Amer., 74, 385-386.

DAVIS, M. A. 1984. The flight and migration ecology of the red milkweed beetle (Tetraopes tetraophthalmus). Ecology, 65, 230-234.

DAVIS, M. A. 1986. Geographic patterns in the flight ability of a monophagous beetle Oecologia, 69, 407-412.

EANES, W. F., GAFFNEY, P. M., KOEHN, R. K. AND SIMON, C. M. 1977. A study of sexual selection in natural populations of the milkweed beetle Tetraopes tetraophthalmus. Christiansen, F. B. and Fenchel, T. M. (eds.), In Measuring Selection in Natural Populations', Springer, New York, pp. 49-64.

EANES, W. F. AND KOEHN, R. K. 1978. An analysis of genetic structure in the monarch butterfly, Danaus plexippus L. Evolution, 32, 784-797.
ENDLER, J. A. 1979. Gene flow and life history patterns. Genetics, 93, 263-284.

JACOBSON, J. W., AND HSIAO, T. H. 1983. Isozyme variation between geographic populations of the colorado potato beetle, Leptinotarsa decemlineata (Coleoptera: Chrysomelidae). Ann. Entomol. Soc. Am., 76, 162-166.

KIMURA, M. AND WEISS, G. H. 1964. The stepping stone model of population structure and the decrease of genetic correlation with distance. Genetics, 49, 561-576.

LANDE, R. 1985. The fixation of chromosomal rearrangements in a subdivided population with local extinction and colonization. Heredity, 54, 323-332.

LARSON, A., WAKE, D. B. AND YANEV, K. P. 1984. Measuring gene flow among populations having high levels of genetic fragmentation. Genetics, 106, 293-398.

LAWRENCE, W. S. 1982. Sexual dimorphism in between and within patch movements of a monophagous insect: Tetraopes (Coleoptera: Cerambycidae). Oecologia, 53, 245-250.

MARUYAMA, T. AND KIMURA, M. 1980. Genetic variability and effective population size when local extinction and recolonization are frequent. Proc. Nat. Acad. Sci., 77, 67106714.

MCCAULEY, D. E. 1983. Gene flow distances in natural populations of Tetraopes tetraophthalmus. Evolution, 37, 12391246.

MCCAULEY, D. E., OTT, J. R., STINE, A. AND MCGRATH, S. 1981. Limited dispersal and its effect on population structure in the milkweed beetle Tetraopes tetraophthalmus. Oecologia, 51, 145-150.

MCDONALD, I.C., KRYSAN, J. L. AND JOHNSON, O. A. 1985. Genetic variation within and among geographic populations of Diabrotica barberi (Coleoptera: Chrysomelidae). Ann. Entomol. Soc. Am., 78, 271-278.

MCKECHNIE, S. W., P. R. EHRLICH AND R. R. WHITE. 1975. Population genetics of Euphydrias butterflies. I. Genetic variation and the neutrality hypothesis. Genetics, $81,571-$ 594.

PASHLEY, D. P., JOHNSON, S. J. AND SPARKS, A. N. 1985. Genetic population structure of migratory moths: the fall armyworm (Lepidoptera: Noctuidae). Ann. Entomol. Soc. Am., 78, 756-762.

PHILliPS, T. W. AND LANIER, G. N., 1985. Genetic divergence among populations of the white pine weevil, Pissodes strob (Coleoptera: Curculionidae). Ann. Entomol. Soc. Am., 78, 744-750.

SELANDER, R. K. AND WHITTAM, T. S. 1983. Protein polymorphisms and the genetic structure of populations. Nei, M. and Koehn, R. K. (eds) In Evolution of Genes and Proteins, Sinauer, Sunderland, MA, pp. 89-114.

SLATKIN, M. 1977. Gene flow and genetic drift in a species subject to frequent local extinctions. Theor. Pop. Biol., 12, 253-262.

Slatkin, M. 1985a. Gene flow in natural populations. Ann. Rev. Ecol. Syst., 16, 393-430.

SLATKIN, M. 1985b. Rare alleles as indicators of gene flow. Evolution, 39, 53-65.

SNYDER, T. P. AND LINTON, M. C. 1984. Population structure in black flies: allozymic and morphological estimates for Prosimulium mixtum and $P$. fuscum (Diptera: Simuliidae). Evolution, 38, 942-956.

SOKAL, R. R. AND ROHLF, F. J. 1981. Biometry. W. H. Freeman, San Francisco.

STOCK, M. W., AMMAN, G. D. AND HIGHBY, P. K. 1984. Genetic variation among mountain pine beetle (Dendroctonus ponderosae) (Coleoptera: Scolytidae) populations from seven western states. Ann. Entomol. Soc. Am., 77, 760-764. 
WARD, P. S. 1980 . Genetic variation and population differentiation in the Rhytidoponera impressa group, a species complex of Ponerine ants (Hymenoptera: Formicidae). Evolution, 34, 1060-1076.

WEIR, B. S. AND COCKERHAM, C. C. 1984. Estimating F-statistics for the analysis of population structure. Evolution, 38 , 1358-1370.

WERTH, C. R. 1985. Implementing an isozyme laboratory at a field station. Va. J. Sci., 36, 53-76.

WRIGHT, S. 1969. Evolution and the Genetics of Populations, Vol. 2. The Theory of Gene Frequencies, Univ. Chicago Press, Chicago.
WRIGHT, S. 1977. Evolution and the Genetics of Populations, Vol. 3. Experimental Results and Evolutionary Deductions, Univ. Chicago Press, Chicago.

WRIGHT, S. 1978. Evolution and the Genetics of Populations Vol. 4. Variability Within and Among Natural Populations, Univ. Chicago Press, Chicago.

ZERA, A. J. 1981. Genetic structure of two species of waterstriders (Gerridae: Hemiptera) with differing degrees of winglessness. Evolution, 35, 218-225. 